\title{
Chapter 15 \\ Transforming the Quality of Workforce in the Textile and Apparel Industry Through Computational Thinking Education
}

\section{Bessie Chong and Ronald Wong}

\begin{abstract}
The goal of introducing computational thinking education in a business setting is not just for technology adoption or invention but it is considered to be a vital skill for empowering employees to address problems critically and systematically. This chapter presents a case study of Esquel Group, a world leader in the textile and apparel sector, to leverage computational thinking (CT) in learning and education to lift staff competence. Esquel believes in the era of Industry 4.0, employees should embrace a new way of thinking by combining logical reasoning and computational power that would empower them with the ability to think independently. Therefore, the "You Can Code" campaign was initiated in 2015 to the staff at all levels with over 1,200 participants from 10 different locations in the first 10 months. By learning how to build a mobile application using MIT App Inventor, the problem-solving learning process is woven into the employees' minds on capacity building. They can learn how to decompose problems, synthesize ideas, and develop an algorithm to solve problems in a structural and creative way. The campaign plays a catalytic role to empower employees as confident users of technology with computational thinking ability and helps the company to nurture a culture of innovation, problem-solving, and collaboration. After the success of the first run, the company tried to further engage young colleagues to stimulate computational thinking and innovation. A series of more comprehensive App Inventor Workshops, including developing mobile apps with Internet of Things and Arduino, was introduced and implemented locally by the young generation. It shows innovation in learning and also demonstrates that Esquel is a nontraditional company which strives to make a difference.
\end{abstract}

Keywords Computational thinking - Vocational learning - App inventor • Computational action $\cdot$ Employee empowerment

Bessie Chong_-Ph.D., Director of Group Training and Talent Management, Esquel Group. Ronald Wong-Former Associate Director of Corporate Communications, Esquel Group.

B. Chong $(\otimes) \cdot$ R. Wong

Esquel Group, 13/F, Harbour Center, 25 Harbour Road, Wanchai, Hong Kong, China

e-mail: Chongbe@esquel.com 


\subsection{Introduction}

The textile and apparel industry has long been regarded as "traditional" and "oldfashioned". It is probably not an industry the new generation aspires to join. Founded in 1978, Esquel started as a shirt maker. Over the last 40 years, Esquel developed the capacity to weave innovative technologies into its people-centric culture. With key production bases established in strategic locations in China, Malaysia, Vietnam, Mauritius, and Sri Lanka, and a network of branches in the US, Europe, and Asia, it offers a one-stop solution, from concept to rack. The annual sales turnover was US\$1.3 billion in 2016 .

Esquel employs more than 57,000 diversified workforce globally, united under the corporate 5E culture-Ethics, Environment, Exploration, Excellence, and Education, and driven by the mission of "Fun People Serving Happy Customers". It operates with an aspiration of "Making a Difference" by creating a positive impact on the employees, communities, and environment. The key employee development strategy is to "groom people from within". As a nontraditional company in a traditional industry, Esquel encourages and empowers employees to innovate and to challenge the status quo by placing great emphasis on learning and people development in facilitating employees to transform and upgrade.

\subsubsection{Business Challenges and Opportunities}

In this day and age, the competition in the industry of textile and apparel manufacturing is fierce. All players face structural challenges from rising labor and material costs, reduced profit margin, and shortened order lead time to the shortage of skilled labors. The rise of fast fashion further disrupts the industry by demanding quicker production cycles and rapid prototyping in small orders. The traditional manufacturing model of long lead time and mass production would find it challenging to survive.

However, the textile and apparel manufacturing industry employed over 75 million people worldwide (Stotz \& Kane, 2015) with an aggregate export amount of over US\$744 billion in 2015 (World Trade Organization, 2015). The industry is still versatile and has huge potential. The question is how do manufacturers stay competitive while enabling sustainable growth amidst the changing environment? Many players in this industry migrates their manufacturing bases and chase after cheap labor to stay competitive. On the contrary, Esquel decided to stay in locations where it has good operating conditions and to cultivate the local talent pool. Esquel strives to improve labor productivity to offset rising wages. The company recognizes the importance to improve the added-value of their people, to provide an inclusive work environment and to pay them well by integrating them into the technology, rather than replacing them with technology. 
The advent of the Fourth Industrial Revolution, also known as Industry 4.0, is associated with the development of global industrial networks, to which all production processes of a wide variety of enterprises will be connected throughout the global supply chain. As a result, computer interaction environment is developed around the modern human (Yastreb, 2015). That means employees would work with cyber-physical systems in a smart factory environment and make use of the Internet of Things (IoT) technology and data collected to streamline operation, empower lean supply chains, and make timely decisions. Ultimately, it will increase supply chain agility, adaptability, and alignment (Lee, 2004) that foster productivity and efficiency. The Fourth Industrial Revolution provides Esquel with an opportunity to sustain its leading position in apparel operations.

While digitalization is bringing great impact to the current business models and operations in the global economy, enterprises need to identify the new value creation opportunity in the process of moving to digital business. Esquel is expected to tap into the digitalization process and optimize its supply chain. However, to facilitate this transformation, it is vital for the employees to have some understanding of computer programming regardless of the profession they are in. Programming will soon become a basic job skill for everyone. The rise of robotics and artificial intelligence calls for new skills and competencies. The new age employees need to be equipped with a new set of skills in order to master technology, explore new possibilities and convert the new ideas into actions. More importantly, we need to train them on how to think systematically through developing their programming ability.

\subsubsection{People Challenges}

Without the right people, the effectiveness of technology would not be maximized or create a positive impact on the business results. Among Esquel's 57,000 employees, only $3.4 \%$ of them are equipped with formal technical qualifications, $12 \%$ of them possess a college diploma or above, with $38 \%$ of them were born before personal computer became popular. The fear of using technology and the shortage of computer-literate employees soon become the barrier of transformation. The challenge is how can we turn employees into confident technology users? How can we empower them to come up with continuous improvement ideas and solve the daily work problems systematically and independently?

A campaign is needed to drive this transformation and to inspire the employees to participate in the revolution. It would be a huge challenge as the target group is highly diversified in culture, age, and education, and spreads over 9 countries in 20 operation sites. It would also be hard to keep the learning momentum. 


\section{2 "You Can Code" Campaign (2015-2016)}

Programming is a skill that helps people learn how to think systematically. By developing computational thinking, people can break down complex problems into manageable parts, look for similarities among and within problems and identify different recommendations step by step. For people who don't have technical knowledge, computational thinking may seem too abstract and programming may seem too technical. The fun and practical "App Inventor" application developed by the Massachusetts Institute of Technology (MIT) was therefore identified as the main driver of this campaign.

The simple graphical interface of App Inventor allows an inexperienced user to create basic, fully functional mobile apps within an hour or less. It transforms the complex language of text-based programming into visual, drag-and-drop building blocks. The easy-to-use interface would change employees' perception of technology adoption and overcome the fear of using IT through this campaign. It further develops their logical reasoning skills, programming capabilities, and more importantly, computational thinking ability. Computational thinking is a fundamental skill for everyone, and it is a way humans solve problems (Wing, 2006). It includes problem decomposition, algorithmic thinking, abstraction, and automation (Yadav, Good, Voogt, \& Fisser, 2017). By equipping employees with computational thinking ability, the company can empower them to become innovative problem solvers, collaborators as well as process owners. Yadav et al. (2017) further stressed that given the irreplaceable role of computing in the working life of today, the competence to solve problems in technology-rich environments is of paramount importance.

There is a need to pay attention to CT as part of the broader concept of digital literacy in vocational education and training, as otherwise adults with only professional qualification may not be well prepared for the working life in the twenty-first century (Yadav et al., 2017, p. 1065).

In Esquel, whether they are workers, general staff, managers, or executives, employees are required to have the right attitude, ability to solve problems and to turn ideas to practical solutions to boost productivity. The "You Can Code" campaign aims to drive a sustained cultural transformation to turn the less technically minded employees into confident users of technology and even the creator of technology.

\subsubsection{Champaign Design and Implementation}

This campaign is designed around how to change $\underline{\mathbf{A}}$ ttitudes, upgrade $\underline{\mathbf{S}}$ kills, and build Knowledge, as shown in Fig. 15.1.

It is impractical if only IT colleagues are involved in providing classroom training and expect employees to change their attitude towards technology. Therefore, the role of IT throughout the campaign is purposely downplayed to convince all employees that programming can be trained to less technically savvy people. An "all-in" 
approach was adopted. The campaign was carried out in five development phases: (1) Pioneering, (2) Modeling, (3) Changing, (4) Cultivating, and (5) Realizing, as shown in Fig. 15.2.

The first round of "You Can Code" campaign started in 2015-2016. The campaign used top-down and bottom-up approaches to engage colleagues from all levels. Platforms included Yammer (Esquel's internal social media networking tool), WeChat, Intranet, company's TV broadcasting, as well as traditional channels such as notice boards and promotional booths at factories were used to educate colleagues and promote the training workshops and "Esquel's App Challenge". Through 28 workshops, over 2,430 training hours were provided to 1,200 participants, including 1,100 employees and 100 of their children from 10 different locations in the first 10 months (Fig. 15.3). The strategy of teaching the children and letting them teach their parents back was proved to be effective. Overall, the impact was encouraging and a lot of positive feedback was received:

Something looks complicated but can be very user-friendly for us in building an app. Useful and valuable information/tools can be shared with the company!

$$
\text { — A Sales Manager in Hong Kong }
$$

The introduction of the online programme 'App Inventor' is useful for non-professionals to build our own app.

— A Senior Sales Executive in Hong Kong

Easy to operate for dummies. All ordinary people can participate in creating an app without the support of IT.

— An Engineering Officer from a Garment Factory in China

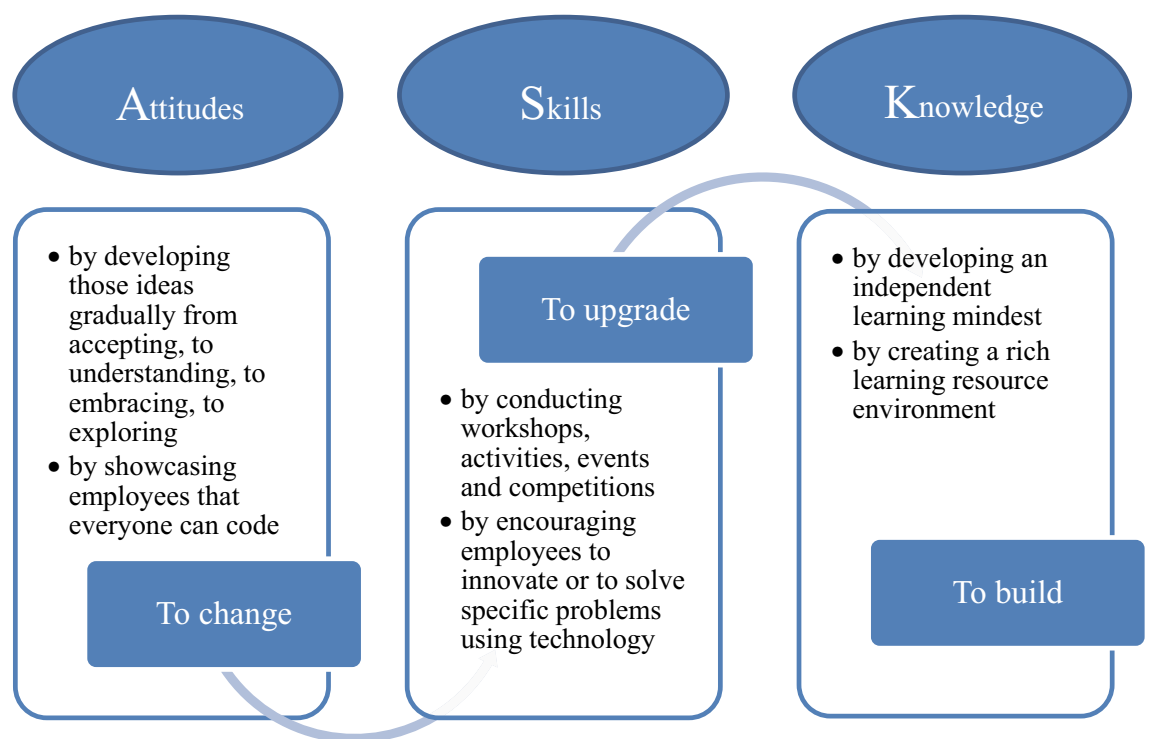

Fig. 15.1 ASK model 


\begin{tabular}{|c|c|c|c|c|}
\hline $\begin{array}{l}\text { Pioneering } \\
\qquad \begin{array}{l}\text { Get } \\
\text { management } \\
\text { buy-in }\end{array}\end{array}$ & $\begin{array}{l}\text { Modelling } \\
\qquad \begin{array}{l}\text { - Set a role- } \\
\text { model - } \\
\text { Everyone can } \\
\text { code }\end{array}\end{array}$ & $\begin{array}{l}\text { Changing } \\
\qquad \begin{array}{l}\text { Train the } \\
\text { super-users } \\
\text { to be the } \\
\text { Change } \\
\text { Agents and } \\
\text { Ambassadors }\end{array}\end{array}$ & $\begin{array}{l}\text { Cultivating } \\
\qquad \begin{array}{l}\text { Promote and } \\
\text { provide } \\
\text { training to } \\
\text { different sites } \\
\text { and people }\end{array}\end{array}$ & $\begin{array}{l}\text { Realizing } \\
\qquad \begin{array}{l}\text { Make the app } \\
\text { idea alive }\end{array}\end{array}$ \\
\hline $\begin{array}{l}\text { Workshops for the senior } \\
\text { management team and } \\
\text { board members were } \\
\text { conducted to collect their } \\
\text { feedback and get their } \\
\text { buy-in. } \\
\text { About } 90 \text { percent of them } \\
\text { attended the training. } \\
\text { Some of them also became } \\
\text { Esquel's pioneers. }\end{array}$ & 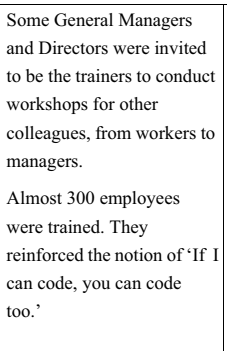 & $\begin{array}{l}\text { About } 50 \text { super-users were } \\
\text { identified and trained to be } \\
\text { the change agents or } \\
\text { ambassadors. } \\
\text { They joined a customized } \\
\text { master trainer course. Then } \\
\text { they delivered training at } \\
\text { different operations. }\end{array}$ & $\begin{array}{l}\text { The master trainers } \\
\text { launched a series of } \\
\text { workshops and fun days for } \\
\text { staff and their kids in order } \\
\text { to cultivate the skills and } \\
\text { mindset. } \\
\text { The ambassadors set up } \\
\text { information and } \\
\text { promotional booths to } \\
\text { educate frontline operators. } \\
\text { A total of almost } 800 \\
\text { people were trained. }\end{array}$ & $\begin{array}{l}\text { The first "Esquel's App } \\
\text { Challenge" Competition } \\
\text { was organized to encourage } \\
\text { the application of the new } \\
\text { skills. Over } 400 \text { mobile app } \\
\text { ideas were submitted. } \\
\text { Many interesting and } \\
\text { practical apps were } \\
\text { developed. }\end{array}$ \\
\hline
\end{tabular}

Fig. 15.2 Five development phases and achievements

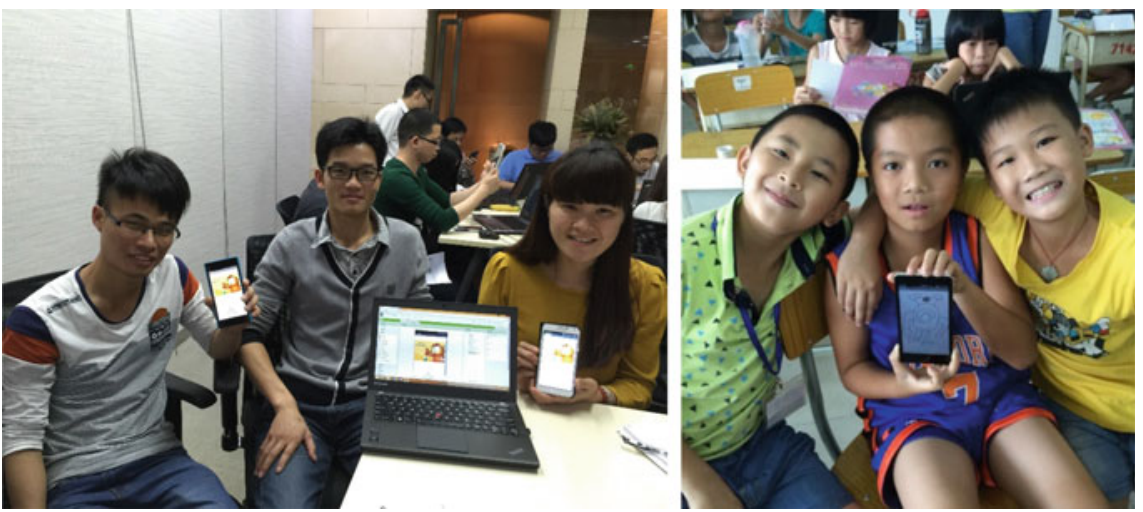

Fig. 15.3 Young colleagues and children of Esquel staff members learn how to code in an hour

\subsubsection{Value Created from the Campaign}

The most important impact of this enterprise-wide campaign is the values created, including attitude change towards technology, employee engagement, employer branding, and process improvement. Many more app ideas from the employees were received. It shows after innovating once, employees are likely to innovate again. Now, non-IT employees can perform part of the IT routine tasks, and some are even able to build prototypes by themselves. This, in turn, allows IT professionals to focus on enterprise-level app development.

The above prototype mobile apps (Table 15.1) were developed by non-IT colleagues based on their local needs. These applications help save time and improve efficiency, while the broader benefits are incalculable. Department heads and IT 
team are reviewing many more bottom-up initiatives from employees to further enhance production efficiency. This campaign is an example of Esquel's commitment to upgrading their workers to become more knowledgeable. And at the same time, the campaign also reinforces Esquel's employer brand as a caring and nontraditional company.

\subsubsection{Employee Empowerment-From Reactive to Proactive, from Follower to Owner}

In previous days, the company needed to actively explore innovative solutions to engage and help employees to embrace technology. Now, we can see employees are actively looking for innovative solutions to improve their work and life.

In the process of developing their own mobile applications, employees started to integrate computational thinking into their everyday work. They took attempts to analyze problems by breaking them down and identifying the root cause, instead of jumping to quick fixes. The story of Yang Hua Mei illustrates how a basic programming training can bring an impact on a sewing worker.

Yang Hua Mei is a young woman from the southwest of China with an immense interest in fashion design and a desire to build a career in apparel manufacturing (Fig. 15.4). After graduating from high school in 2014, she joined Esquel as a sewing worker and brought many undeveloped fashion ideas that were waiting to be realized. During the campaign, Hua Mei learned the basic technical skills, such as computational thinking, logical reasoning, and simple programming to turn her undeveloped fashion ideas to life. By the end of the campaign, Hua Mei and two other colleagues built an app allowing users to mix-and-match their wardrobe.

Before joining 'You Can Code', I didn't even know what was meant by an 'app'! I have learned so much in the program, and now I appreciate the work of the technology gurus-no matter how simple an app might seem, building one requires many steps and logical thinking!, said Hua Mei.

She also realized that the basic programming technique equipped her with computational thinking ability, which in turn helped her to become an independent thinker. As a sewing worker, from time to time, she faced problems in operating her sewing machine and managing the sewing quality. Before she learned how to code, whenever she came across problems, she would simply ask the technician to fix it or change some machine parts by herself. She had never bothered to understand the problems, the root causes, and thought about how to prevent them in the future. But now, she becomes proactive in learning technical skills and starts to integrate the computational thinking ability to solve her daily work problems. She also aspires to evolve from a sewing worker to a technician one day. 
Table 15.1 Examples of the mobile apps developed in this campaign

\begin{tabular}{|c|c|}
\hline Applications & Functions \\
\hline 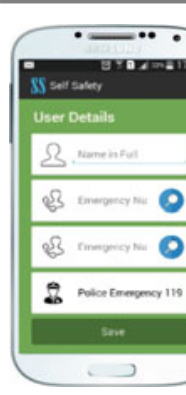 & $\begin{array}{l}\text { Safety app for women } \\
\text { A Sri Lankan colleague developed this app with a GPS function for } \\
\text { female colleagues leaving work at night. Female colleagues can set } \\
\text { the time and contact and if they do not arrive home at the specified } \\
\text { time, the contact number will be dialed. }\end{array}$ \\
\hline (5) & $\begin{array}{l}\text { Parking space and free bike locator app } \\
\text { This app helps colleagues to find a parking spot or an available } \\
\text { bicycle to be borrowed near operation sites through its real-time } \\
\text { parking space and bicycle availability information. }\end{array}$ \\
\hline 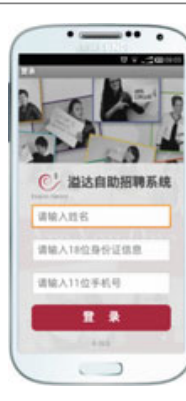 & $\begin{array}{l}\text { Recruitment app } \\
\text { This app helps Human Resources colleagues to streamline some } \\
\text { manual work during the recruitment process, such as marking test } \\
\text { paper and personnel data entry. Applicants can key in their basic } \\
\text { personal information in the app and conduct some simple aptitude } \\
\text { tests. }\end{array}$ \\
\hline 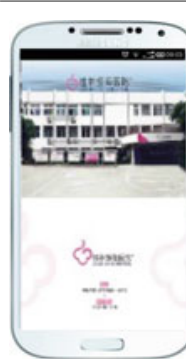 & $\begin{array}{l}\text { Newborn baby photo sharing app } \\
\text { This app functions like a greeting card. It allows new parents (the } \\
\text { colleagues) to send their first newborn baby's photo to their friends } \\
\text { with the baby information and Esquel's hospital logo. }\end{array}$ \\
\hline
\end{tabular}



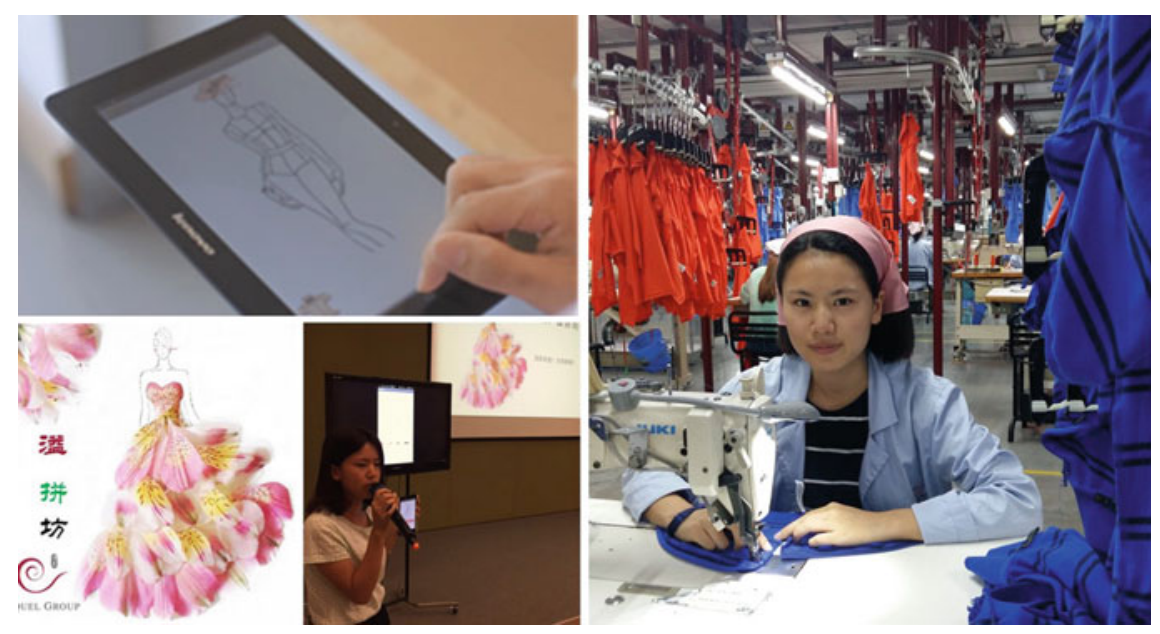

Fig. 15.4 Interface of the wardrobe application developed by Yang Huamei's team and a photo of Yang Hua Mei at work and training

\subsection{From Computational Thinking to Computational Action}

This first phrase of "You Can Code" campaign was completed in 2016. It helped the employee to leverage technology to solve their daily issues and improve productivity. Indeed, it started the momentum. The rise of mobile app initiatives after "You Can Code" campaign is the result of the empowerment through computational action.

\subsubsection{Development of Esquel Carpool App}

Esquel Carpool App is an impactful commercialized mobile app developed by a factory colleague using software such as Objective-C, Java, and Node.js. It aims in solving the air pollution, traffic congestion and carbon footprint challenges. The impact is enormous.

According to the data provided by the Chinese Environmental Protection Bureau, 15-30\% of the pollution comes from the car emission (Chinese Environmental Protection Bureau, 2016). With an exponentially increasing number of cars, traffic congestion is now seen everywhere in China.

Esquel's largest operation base is located in Gaoming, Foshan. It has about 23,000 employees working in several factories that are spread over the city of Gaoming. Around $40 \%$ of Esquel employees work and live there. Employees commute from home to these working locations in similar timing and similar routes every day. Many of them take company shuttle or city bus and always suffer from waiting in a long 


\section{Esquel Carpool}
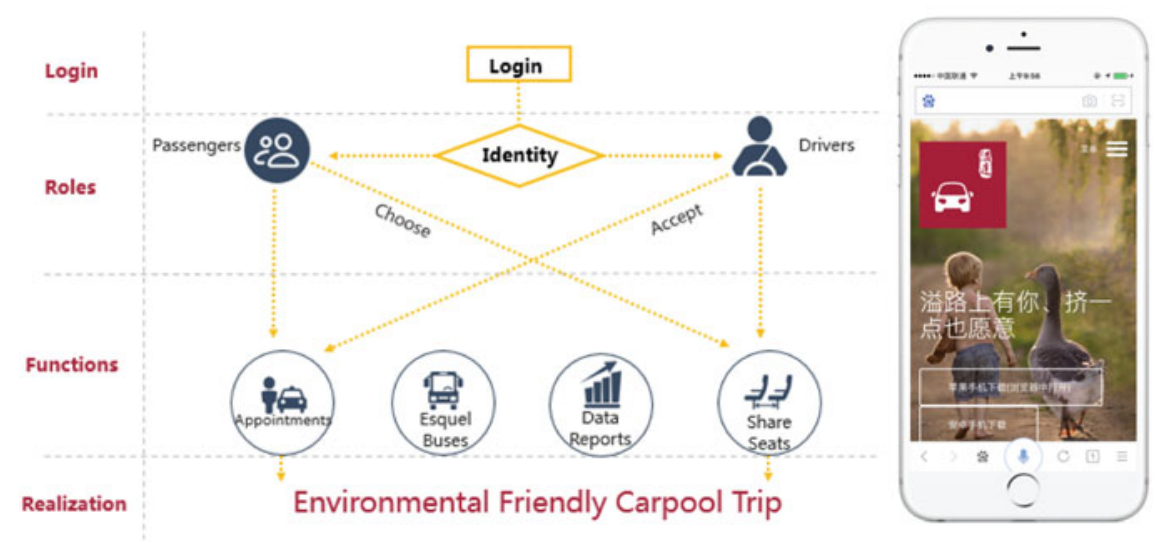

Fig. 15.5 Design map and login page of Esquel Carpool application

line under the sun, rain, and wind. Commuting can easily take up half an hour or even one full hour per trip. For those 2,000 employees with their own private cars, the situation is not better than the others. Driving to work is not at all pleasant when they have to be stuck in traffic and fight for the limited 200 parking spaces available around the factories. Most of the time, employees have to park far away and take another 10-minute walk back to the office.

How can Esquel make a difference for the colleagues so that they can save time in waiting for the bus, fighting for the traffic or looking for parking space? How can they save on gasoline bills while reducing carbon footprint?

Can something be done to change their lifestyle and behavior, reduce the environmental impact, and inspire others to contribute to building a green city?

\subsubsection{The Idea of Esquel Carpool App}

To tackle the above challenges, an employee in Gaoming, Guangdong, China factory initiated an idea to develop an app to facilitate the carpool process in Esquel. Inspired by the "You Can Code", the Esquel Carpool App was born in June 2016 (Fig. 15.5). It shows that colleague looks proactively at the technology for improving their lives and finding ways to develop this application after the "You Can Code" campaign.

To start with, employees can use their staff ID to login, and select to be either the passengers or drivers. Passengers can publish their needs (e.g., where and when they want to go) or select the available seats from the drivers. Drivers can publish the number of available seats to the passengers, or directly select the passengers 
through the app. After that, they can form a group chat to communicate directly for boarding arrangement. What's more, this app can also share the real-time location of the company bus and show the carpool usage report.

\subsubsection{Impact from Esquel Carpool App}

Within the first 24 months, this app has already recorded more than 139,083 carpools, with the saving of more than 105,703 liters of gasoline. It avoided the emission of 243.1 tons of carbon dioxide. This app helps to realize the benefits of carpooling on saving the environment. More importantly, it provides a platform to make a connection with colleagues from different departments that promotes the caring culture.

The company is committed to provide this app for free to any companies and organizations, and the app is readily available in the open-source community GitHub.

\subsection{From Programming to Internet of Things}

\subsubsection{Success of "You Can Code" Campaign}

Esquel is the first commercial entity to adopt App Inventor to train employees in computational thinking. Even though computational thinking is rather conceptual and hard to develop in a short period of time, the company has managed to change attitudes, upgrade skills, and build knowledge through the development of the mobile app.

The first round of "You Can Code" campaign received an initial success. The "all-in" approach encouraged everyone to engage in the campaign. Many employees, including board members and sewing workers, joined the fun and easy "1-hour programming" workshops. Employees' kids were also invited, who in turn, influenced and motivated their parents to learn programming. The campaign engaged people from primary students to Ph.D. graduates aged from 6 to over 60 .

It successfully engaged all levels of staff members by enrolling board members and senior managers as pioneers, ambassadors, and trainers. Some even modeled the skills and trained their teams at their sites. They jointly promoted the notion of "If I can code, you can code too", and successfully changed the perception that senior staff are conservative and less tech-savvy. 


\subsubsection{Continuity of "You Can Code"}

The project team understands that what they have done is just a small step. In order to build a programming culture and independent critical thinking skills, more efforts are required. Indeed, the project team also understands what the employees have learned in the 1-hour App Inventor workshop is not sufficient. The next step is how to deep dive into what they have learned to embrace the computational thinking skills and unleash their creativity. Thus, the project team needs to provide a platform to enable the participants to organize and analyze information logically and creatively. Then, they can break the challenges down into small pieces, and approach them by using programmatic thinking techniques. The exercise would reiterate the interest of the participants to learn, create, and modify their own applications.

With this in mind, the "You Can Code 2.0" campaign started in November 2017. The project team aims to take one-step further from creating a simple mobile application to developing a stimulated real-life application in the workplace. The company plans to teach colleagues essential skills to build a microcontroller-based embedded system, which is monitored by a mobile app developed by App Inventor.

The project team aims to train the participants basic programming technique connected with physical devices as an example. Then, the participants can replicate the setting and methodology to create their own IoT or Arduino prototypes. More importantly, the project team wants to teach the logic behind those programming techniques. Once the participants figure out most of the intelligent production and process systems found in the work environment are in fact programmed by the basic computer logic, they will have confidence in making recommendations and asking questions on the current practices and systems.

\subsubsection{You Can Code 2.0}

The explosive growth of the "Internet of Things" is changing how things are being operated. It allows people to innovate new designs and products at work and home. The capturing of big data means a huge opportunity for operation efficiency improvement. Esquel has many "Internet of Things" applications, for example, auto-guided vehicles and drones are adopted in the factory for transportation use. At the backend, a knowledge base is established and linked to the intelligent control system, which is further connected to smart devices. Thus, if the colleagues can understand the way to connect those devices to the backend system through the internet, they will be motivated to build applications and devices that could ease the manual work. Indeed, IoT comes with a combination of software and hardware. Colleagues can apply what they have learned to program the Arduino and build a smart system by connecting basic sensors and actuators for automation.

To launch the "You Can Code 2.0" workshop, a progressive and systematic learning path was designed. Three levels of workshop, according to the difficulty and 


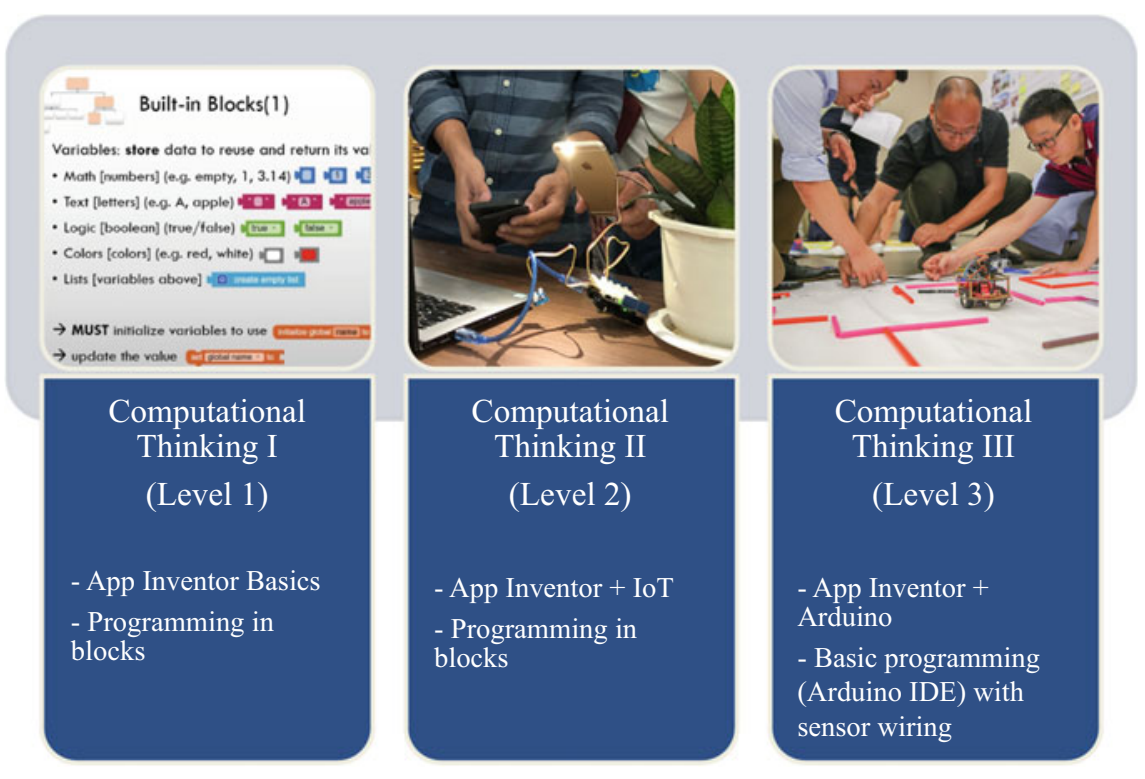

Fig. 15.6 Three levels of workshops for "You Can Code 2.0"

complexity of the app, were organized (Fig. 15.6). We targeted to recruit those who have not joined the App Inventor workshop before or those who are interested in using technology. As a result, majority of participants are young generation.

Level 1 workshop is a beginner course focusing on basic App Inventor techniques. It aims to help new participants to equip with basic skills, and to refresh the previous practice. At this level, not all block building instructions are given, except basic functions and interface of the App. Some instructions are deliberately left blank, and only partial block building instructions are provided. Participants need to complete the instructions and build the blocks according to their needs and understanding. Custom design interface and functions are recommended to demonstrate their creativity, the comprehensiveness of logic, and the ability of the computational thinking.

Level 2 workshop focuses on programming technique applications on a microecosystem. Participants are required to develop a Smart Plantation Monitoring System based on IoT to monitor a small plant growth. The mobile app collects humidity and light data from the plant via a sensor node. Colleagues will then base on the data collected to build a decision-making mechanism. With the combination of the wireless sensor network, embedded development, and data transmission, colleagues will receive recommendation instantly, such as watering or giving more light to keep the plant healthier. This workshop further examines how computer programming would aid decision-making through an ecosystem experiment.

Level 3 workshop focuses on providing a simulated operation environment for problem-solving. Participants are taught on how to program the Arduino to perform 
certain tasks, such as turning on the lights, making a device turns, moving forward and backward, and escaping from a maze.

After the completion of all three levels of the workshop, a second round of "Esquel's App Challenge" competition will be organized to further stimulate their creativity and problem-solving ability. To facilitate a series of workshops to different locations, more ambassadors and change agents are identified. Therefore, Esquel has incorporated this basic App Inventor training into their management trainee (MT) training curriculum. After receiving the training, the MTs will be responsible to teach colleagues at their local sites. About 100 MTs, spreading across different locations will have an exposure to the technology and take ownership in fostering the learning culture in their own locations. The project team strongly believes that peer learning is more effective in promoting the use of technology and will overcome their fear of technology adoption. More local needs on improving work-related or life-related issues can be solved by themselves with flexibility. The active participants will be the voice and the next generation of leaders who strive make a difference.

\subsection{Conclusion}

Esquel is forward-looking by building future skills to enhance productivity and uplift employees' competence to master technology. The "You Can Code" campaign upskills employees, opens their minds to technology and equips them for life. It also opens the potentials for organizational digital transformation. This aligns with the company's vision of making a difference and empowers teams for continuous learning and problem-solving. Esquel is committed to boost the programming skills of its colleagues and build its organizational capability. The computational thinking training will be used as a core curriculum of the Esquel University, the enterprise university, to provide a standardized learning experience to all Esquel employees in the future. It also supports the company's determination in moving towards a digital organization.

This is just the beginning of Esquel using modern technology beyond work to make lives better. The "You Can Code" campaign provides an opportunity to colleagues so they can come up with their own initiatives to make Esquel a better working environment and eventually benefit the local community. Different departments and operations are actively exploring and developing new mobile applications to improve work efficiency and work-life quality; and at the same time, the Company is coordinating a steering committee to embrace all different mobile apps under one master app, namely Esquel Pass, to provide a one-stop solution to employees.

Looking to the future, Esquel will continue to empower employees to innovate and solve problem critically and independently with computational thinking and technique. 


\section{References}

Chinese Environmental Protection Bureau. (2016). 我国雾霧成因及对策. 紫光阁(3), 82-83. Retrieved from http://kns.cnki.net/KCMS/detail/detail.aspx? dbcode $=$ CJFQ \&dbname $=$ CJFDLAST2016 \&filename $=$ ZIGU201603061\&uid $=$ WEEvREcwSIJHSldRa1FhdkJkcGkzRm1aVDg1WXA3WG9XMmJobkw3NEM5UT0= \$9A4hF_YAuvQ5obgVAqNKPCYcEjKensW4ggI8Fm4gTkoUKaID8j8gFw!!\&v= MjU1MTJySTIEWIISOGVYMUx1eFITNORo.

Lee, H. L. (2004). The triple-A supply chain. Harvard Business Review, 82(10), 102-113.

Stotz, L., \& Kane, G. (2015). Facts on the global garment industry. Retrieved February, 2015, from https://cleanclothes.org/resources/publications/factsheets/general-factsheet-garmentindustry-february-2015.pdf.

Wing, J. M. (2006). Computational thinking. Communications of the ACM, 49(3), 33-35.

World Trade Organization (2015). Retrieved 2015, from http://stat.wto.org/StatisticalProgram/ WSDBViewData.aspx ?Language $=$ E.

Yadav, A., Good, J., Voogt, J., \& Fisser, P. (2017). Computational thinking as an emerging competence domain. Retrieved January, 2017, from https://www.researchgate.net/publication/ 307942866.

Yastreb, N. (2015). The internet of things and the fourth industrial revolution: the problem of humanitarian expertise. Journal of Scientific Research and Development, 2(8), 24-28.

Open Access This chapter is licensed under the terms of the Creative Commons Attribution 4.0 International License (http://creativecommons.org/licenses/by/4.0/), which permits use, sharing, adaptation, distribution and reproduction in any medium or format, as long as you give appropriate credit to the original author(s) and the source, provide a link to the Creative Commons license and indicate if changes were made.

The images or other third party material in this chapter are included in the chapter's Creative Commons license, unless indicated otherwise in a credit line to the material. If material is not included in the chapter's Creative Commons license and your intended use is not permitted by statutory regulation or exceeds the permitted use, you will need to obtain permission directly from the copyright holder.

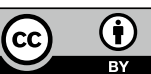

